\title{
A Case of Bilateral Adrenal and Pleural Metastases from Prostate Cancer
}

\author{
Takashi Kawahara $^{\mathrm{a}}$ Hiroki Taguchi $^{\mathrm{b}}$ Takuya Yamagishi $^{\mathrm{b}}$ \\ Koichi Udagawa ${ }^{\mathrm{b}}$ Hideki Ouchi $^{\mathrm{b}}$ Hiroshi Misaki $^{\mathrm{b}}$ \\ aDepartment of Urology, Yokohama City University Graduate School of Medicine,

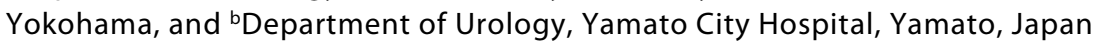

\section{Key Words \\ Prostate cancer · Adrenal metastasis · Pleural metastases}

\begin{abstract}
Our case was 65 years old. At check-up, a high PSA level of $515 \mathrm{ng} / \mathrm{ml}$ was observed, the patient was diagnosed with having clinical stage $D$ prostate cancer and a Maximum Androgen Blockade (MAB therapy) was started. In response to the exacerbated prostate cancer, we started a therapy involving the administration of $8 \mathrm{mg} / \mathrm{kg}$ body weight of dexamethasone and $55 \mathrm{mg} / \mathrm{m}^{2}$ of docetaxel every 3 weeks. After completing 8 courses, an enlargement of the bilateral adrenal tumor was observed, and after completing 12 courses, a pleural tumor was discovered and the PSA level was also increased. The patient was therefore diagnosed with having bilateral adrenal metastasis and pleural metastasis of prostate cancer through diagnostic imaging. So far, there have been no reports of multiple occurrences of prostate cancer in the adrenal glands and the pleura, thus making this case the first such case.
\end{abstract}

\section{Introduction}

It has been reported that in autopsy cases of prostate cancer patients, adrenal metastasis is observed in $17-20 \%$ of the cases and pleural metastasis is observed in around $20 \%$ of the cases $[1,2]$. However, there are few reports on clinical cases, and the case described here is only the fourth case of adrenal metastasis and the second case of pleural metastasis. As far as we could determine based on an extensive literature search, there have been no reports of prostate cancer that developed simultaneous metastases in both the adrenal glands and the pleura, and we herein report this case with a few bibliographical considerations. 


\begin{tabular}{|c|c|c|c|}
\hline $\begin{array}{l}\text { Cose Reports in } \\
\text { incenty }\end{array}$ & $\begin{array}{l}\text { Case Rep Oncol 2009;2:217-219 } \\
\text { D0I: } 10.1159 / 000258964\end{array}$ & Published online: November 21, 2009 & \begin{tabular}{|l} 
@ 2009 S. Karger AG, Basel \\
ISSN 1662-6575 \\
www.karger.com/cro
\end{tabular} \\
\hline
\end{tabular}

\section{Case Report}

Our case was 65 years old. He became aware of increased urinary frequency starting in 2004 but did not undergo any specific check-ups. In 2006, a high PSA level was observed and the patient was referred to our hospital for a check-up. At the check-up, a high PSA level of $515 \mathrm{ng} / \mathrm{ml}$ was observed and a transrectal prostate needle biopsy was performed. The pathological finding was moderately differentiated prostate cancer with a Gleason score of $7(4+3)$. Although bone metastasis was observed, there was no lymph node metastasis or any distant metastasis. The patient was diagnosed with having clinical stage D prostate cancer, and a Maximum Androgen Blockade (MAB therapy) was started. The cancer became exacerbated 1 year after starting the MAB therapy. In response to the exacerbated prostate cancer, we started a therapy involving the administration of $8 \mathrm{mg} / \mathrm{kg}$ body weight of dexamethasone and $55 \mathrm{mg} / \mathrm{m}^{2}$ of docetaxel every 3 weeks. After completing 8 courses, an enlargement of the bilateral adrenal tumor was observed, and after completing 12 courses, a pleural tumor was discovered and the PSA level was also increased. The patient was therefore diagnosed with having bilateral adrenal metastasis and pleural metastasis of prostate cancer through diagnostic imaging (fig. $1 \mathrm{a}, \mathrm{b})$.

\section{Results}

Although it has been reported that $17-20 \%$ of all autopsy cases of prostate cancer patients have adrenal metastasis, this case is only the fourth known clinical case, following cases reported by Navarro et al., Sakamoto et al., and Ishii and Hiratsuka [3-5]. Long and Husband [6] reported that out of 398 cases of prostate cancer in which an abdominal CT was performed, adrenal metastasis was observed in only 1 case. Although many cases of unilateral pulmonary metastasis have been reported, there has been only 1 case of pleural metastasis in Japan, reported by Takagi et al. [7]. However, it is believed that cases of pulmonary metastasis include cases that also involve pleural metastasis, and that the actual number of cases of pleural metastasis is therefore higher than reported so far.

So far, there have been no reports of multiple occurrences of prostate cancer in the adrenal glands and the pleura, thus making this case the first such case.

Fig. 1. a Computed tomography (CT) of the chest. Bilateral pleural metastases (arrows). b CT of the abdomen. Bilateral adrenal metastases (arrows).
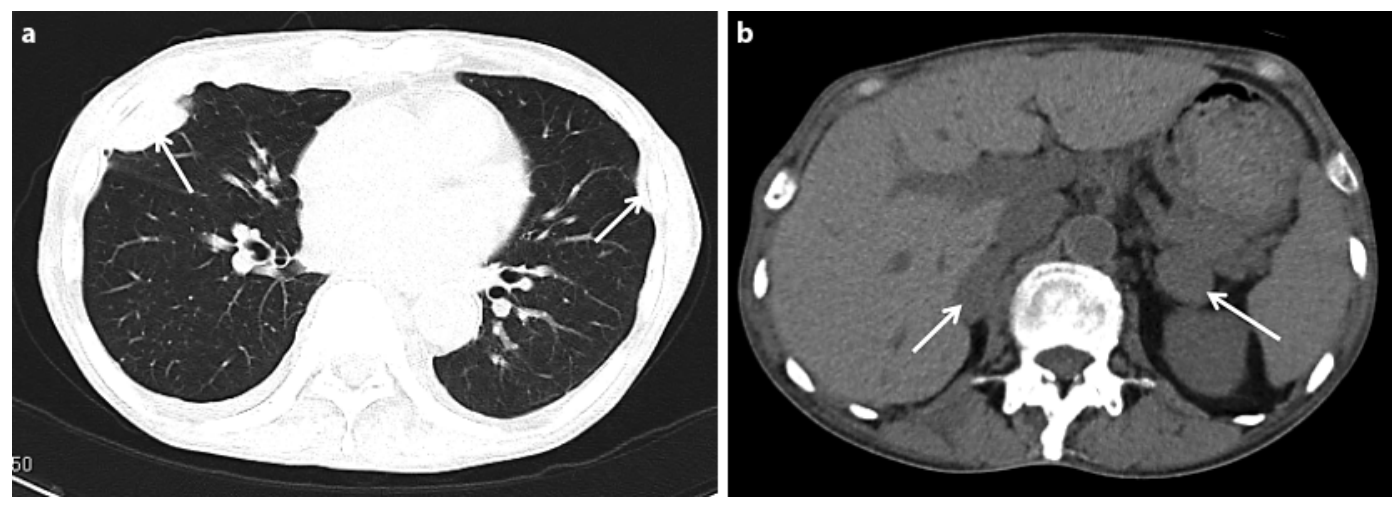


\section{References}

1 de la Monte SM, Moore GW, Hutchins GM: Metastatic behavior of prostate cancer: cluster analysis of patterns with respect to estrogen treatment. Cancer 1986;58:985-993.

-2 Bubendorf L, Schöpfer A, Wagner U, et al: Metastatic patterns of prostate cancer: an autopsy study of 1,598 patients. Hum Pathol 2000;31:578-583.

-3 Navarro M, Felip E, Gracia L, et al: Addison's disease secondary to prostatic carcinoma. A case report. Tumori 1990;76:611-613.

-4 Sakamoto N, Eto M, Ando S: Surgical excision of a metastatic adrenal lesion in a patient with prostatic cancer. Int J Urol 1999;6:38-40.

5 Ishii T, Hiratsuka Y: Bilateral adrenal metastases from prostatic carcinoma during chemoendocrine therapy (in Japanese). Rinsho Hinyokika 2003;57:157-159.

6 Long MA, Husband JES: Features of unusual metastases from prostate cancer. $\mathrm{Br}$ J Radiol 1999;72:933-941.

7 Takagi Y, Hashimoto J, Kurokawa T, et al: Prostate cancer with multiple pulmonary and pleural metastases: a case report (in Japanese). Rinsho Hinyokika 2004;58:769-771. 